\title{
SORPTION OF HYDROPHOBIC ORGANIC POLLUTANTS IN SATURATED SOIL SYSTEMS
}

\author{
CASS T. MILLER and WALTER J. WEBER Jr.
}

Department of Environmental Sciences and Engineering, University of North Carolina, Chapel Hill, NC 27514 (U.S.A.)

Environmental Engineering Program, The University of Michigan, Ann Arbor, MI 48109

(U.S.A.)

(Received January, 1985 ; revised and accepted September 30,1985 )

\section{ABSTRACT}

Miller, C.T. and Weber Jr., W.J., 1986. Sorption of hydrophobic organic pollutants in saturated soil systems. In: D.L. Macalady (Editor), Transport and Transformations of Organic Contaminants. J. Contam. Hydrol., 1: 243-261.

Sorption equilibria and rates were characterized for a matrix of four aquifer sands and two slightly to moderately hydrophobic organic solutes (nitrobenzene and lindane), and the effects of sorption on the behavior of these solutes in saturated systems of the soils were determined. Experimental data were used to test and evaluate a variety of mathematical models for predicting contaminant fate and transport in groundwater systems.

Observed equilibrium relationships between soil and solution phase solute concentrations were found to be described best by the nonlinear Freundlich isotherm model. It was further determined that the sorption process in the systems tested is rate controlled, requiring several days to approach equilibrium in completely mixed batch reactors. Subsequent modeling of solute transport in continuous flow soil column reactors was found to be most successful when rate-controlled models were used, the best results were obtained with a dual-resistance model incorporating the coupled mass transport steps of boundary-layer and intraparticle diffusion.

\section{INTRODUCTION}

The increasingly widespread occurrence of groundwater contamination has fostered a general need for a better understanding of factors which control contaminant fate and transport in subsurface environments. For hydrophobic organic compounds, a major class of groundwater pollutants, sorption is the most significant of several reaction and transformation mechanisms which impact movement and fate. Appropriate account of sorption processes must be made for accurate analysis of contaminant transport, reliable assessment of risk, and for selection and design of appropriate remedial measures.

Characterization of the sorptive partitioning of a contaminant between soil and groundwater phases requires description of the nature of equilibrium conditions ultimately attained as well as the rates at which these conditions are approached. It has in the past been common for purposes of modeling 
simplification to assume that sorptive partitioning in groundwater systems can be represented by a linear relationship which is approached rapidly enough to permit the further assumption of local equilibrium. Recent work by Karickhoff (1980), Miller (1984) and Miller and Weber (1984) has suggested that these assumptions may not be justified for many systems. The research described here has focused on the characterization of sorption rates and equilibrium relationships for several typical aquifer sands and two representative hydrophobic pollutants, lindane and nitrobenzene. A variety of mathematical models have been evaluated with respect to their suitability for describing observed equilibrium and rate relationships. These include the linear, Freundlich, and Langmuir equilibrium models, and first-order, parallel equilibrium/first-order, and dual-resistance mass transfer rate models.

\section{SOIL PROPERTIES}

Four glacially deposited Wisconsin Age aquifer sands were investigated. Sands were chosen because a substantial percentage of those aquifers which supply drinking water are in sand formations, and because advective fluxes tend to be greater through granular horizons than through other soil formations, thereby facilitating contaminant transport over wide geographic areas.

The soil samples were characterized by grain-size distribution, uniformity, hydraulic conductivity, organic carbon content, and cation exchange capacity . The physical properties were determined by standard ASTM (1980) procedures. Cation exchange capacity was determined by the conductometric barium saturation $\rightarrow$ sulfate titration method (Black, 1965). Organic carbon analyses were performed using a persulfate oxidation technique (Oceanography International Corporation, 1975). The results of these characterizations are summarized in Table 1.

\section{SOLUTE PROPERTIES}

Lindane $(\gamma-1,2,3,4,5,6$-hexachlorocyclohexane) and nitrobenzene were chosen as representative pollutants for the study. Lindane is a slightly polar chlorinated insecticide manifesting low volatility and solubility, and a relatively high degree of hydrophobicity. Nitrobenzene, a compound commonly used in the manufacturing of dyes, shoe polish, rubber, drugs, and solvents, is somewhat more volatile, much more soluble, and partitions less extensively to organic phases than does lindane. The properties of lindane and nitrobenzene are summarized in Table 2.

All solute solutions were made up in a $0.01 \mathrm{~N}$ background of calcium ion and were buffered to a $\mathrm{pH}$ of 8 with a boric acid-sodium borate solution. This procedure eliminated potential effects of $\mathrm{pH}$ on sorption and maintained 


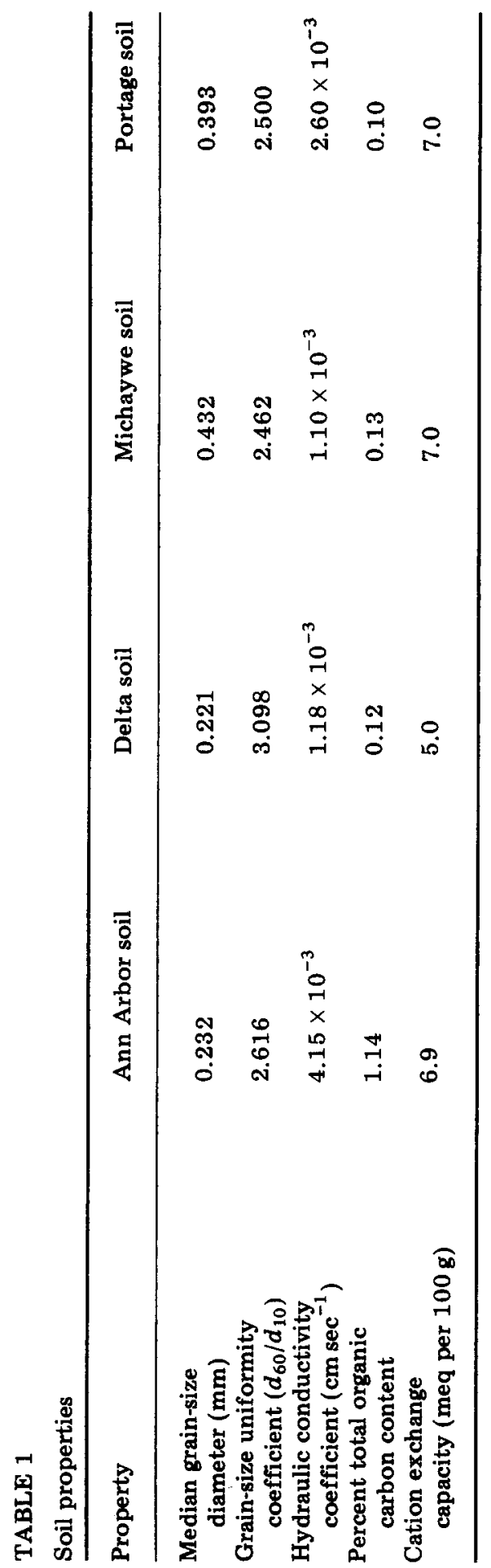


TABLE 2

Solute properties

\begin{tabular}{llc}
\hline & Compound & \\
\cline { 2 - 3 } Property & lindane & nitrobenzene \\
\hline $\begin{array}{c}{ }^{\mathrm{a}} \text { Log octanol water partition } \\
\text { coefficient }\end{array}$ & 3.72 & 1.88 \\
$\begin{array}{c}\mathrm{b} \text { Henry's constant } \\
\left(\text { mole }^{-3} \text { atm }^{-1}\right)\end{array}$ & $4.8 \times 10^{-7}$ & $2.2 \times 10^{-5}$ \\
$\begin{array}{c}\mathrm{b} \text { Aqueous solubility at } \\
20^{\circ} \mathrm{C}\left(\mathrm{mg} \mathrm{l}^{-1}\right)\end{array}$ & 7.3 & 2000.0 \\
\hline
\end{tabular}

${ }^{a}$ Hansch and Leo (1979). ${ }^{b}$ Lyman et al. (1982).

a constant calcium level within the soil to ensure reproducible conditions from one experiment to another.

\section{EXPERIMENTAL}

Analyses of both lindane and nitrobenzene were performed with a Hewlett Packard 5880 A gas chromatograph equipped with an electron capture detector $\left(\mathrm{Ni}^{63}\right)$. Solution phase detection limits for the heavily chlorinated lindane molecule are quite low (about $1 \mu \mathrm{g} \mathrm{l}^{-1}$ ), with exact levels being a function of hexane extraction ratios. That nitrobenzene is not halogenated makes electron capture less sensitive for this compound than for lindane, with detection limits for the solution phase typically being about $10 \mu \mathrm{g}^{-1}$. Analyses were performed at column temperatures of $190^{\circ} \mathrm{C}$ for lindane and $130^{\circ} \mathrm{C}$ for nitrobenzene, and in both cases an argon (95\%)-methane (5\%) mixture was employed as the carrier gas.

Tests performed on potential reactor construction materials of plexiglass, Tygon ${ }^{\circledR}$, stainless steel and Teflon ${ }^{\circledR}$ showed that lindane sorbed on each of these materials, but to a lesser extent on Teflon than on the other three. Tests performed with nitrobenzene showed much less sorption by these potential experimental materials with Teflon showing the least sorption. Solute contact areas in all reactors were therefore limited to borosilicate glass wherever possible, with Teflon used as the alternative when glass construction was not feasible. While some sorption of lindane still occurred on borosilicate, the glass reactor impact was minimized by working at high soil to solution rates. High soil to solution ratios yield a smaller concentration in the solution phase and hence less reactor impact. Very small amounts of nitrobenzene sorption to borosilicate glass occurred but caused no significant experimental difficulties.

Completely mixed batch reactor (CMBR) experiments employing individual reactors for each data point (bottle-point technique) were conducted in 50-ml Pyrex ${ }^{\circledR}$ or Kimax ${ }^{\circledR}$ glass centrifuge bottles. These experiments consisted 
of both rate investigations and equilibrium isotherm studies. The bottlepoint rate studies were performed by preparing a number of identical bottle reactors, each containing an equal volume and concentration of solute solution and identical weights of soil. The reactors were tumbled to maintain completely mixed conditions until each (with associated replicates) was removed at a different time (one hour to several days) subsequent to initiation of an experiment for analysis of residual solution phase concentration.

Hexane extraction of the soil phase for each solute and subsequent analysis for solid phase mass was performed on several occasions. The results of these studies yielded less than a ten percent loss of mass in all cases.

CMBR bottle-point isotherms were performed by placing a known and equal weight of soil in each of 20-40 borosilicate centrifuge bottles, adding constant volumes of solution of known concentration of solute to each, and tumbling all bottles long enough to ensure that the sorption process attained equilibrium. The reactors were then centrifuged for separation of the soils from the aqueous phase.

Soil columns consisting of aquifer sands packed in $2.5-\mathrm{cm}$ diameter glass tubes were used to investigate contaminant sorption characteristics in systems involving both advective and dispersive flow (plug flow with dispersion reactors, PFDRs). All columns, tubing, valves and sampling vessels were constructed of borosilicate glass to minimize extraneous sorption. The fine-grained soil was packed between small layers of glass beads to prevent migration from the soil column. The effluent concentration was monitored continuously by a time-regulated fraction collector; discrete influent sampling was done by valve regulation. A peristaltic pump was employed to provide a constant flow rate to the columns, with adjustments in flow accomplished by varying the pump tube size and motor speed. A schematic illustration of the PFDR soil columns is given by Fig. 1.

Chloride was used as a tracer to determine the advection and dispersion characteristics of the PFDRs. This was accomplished by equilibrating the column with a flow of an organic-free feed solution which was $0.01 \mathrm{~N}$ in calcium sulfate and then introducing an organic contaminant solution which was $0.01 \mathrm{~N}$ in calcium chloride. The chlorides were analyzed with an Orion ${ }^{\circledR}$ internally referenced electrode and a digital $\mathrm{pH}$ meter. Desorption was measured after the sorption interval by halting the input of the organic contaminant/calcium-chloride solution and reinitiating the feed of calcium sulfate solution.

\section{EQUILIBRIUM STUDIES}

Sorption isotherms were measured for a matrix of six soil-solute systems, including lindane in combination with each of the four soils and nitrobenzene with the Ann Arbor and Delta soils. Each set of isotherm data was analyzed for fit to the linear, Freundlich, and Langmuir models, given respectively in 


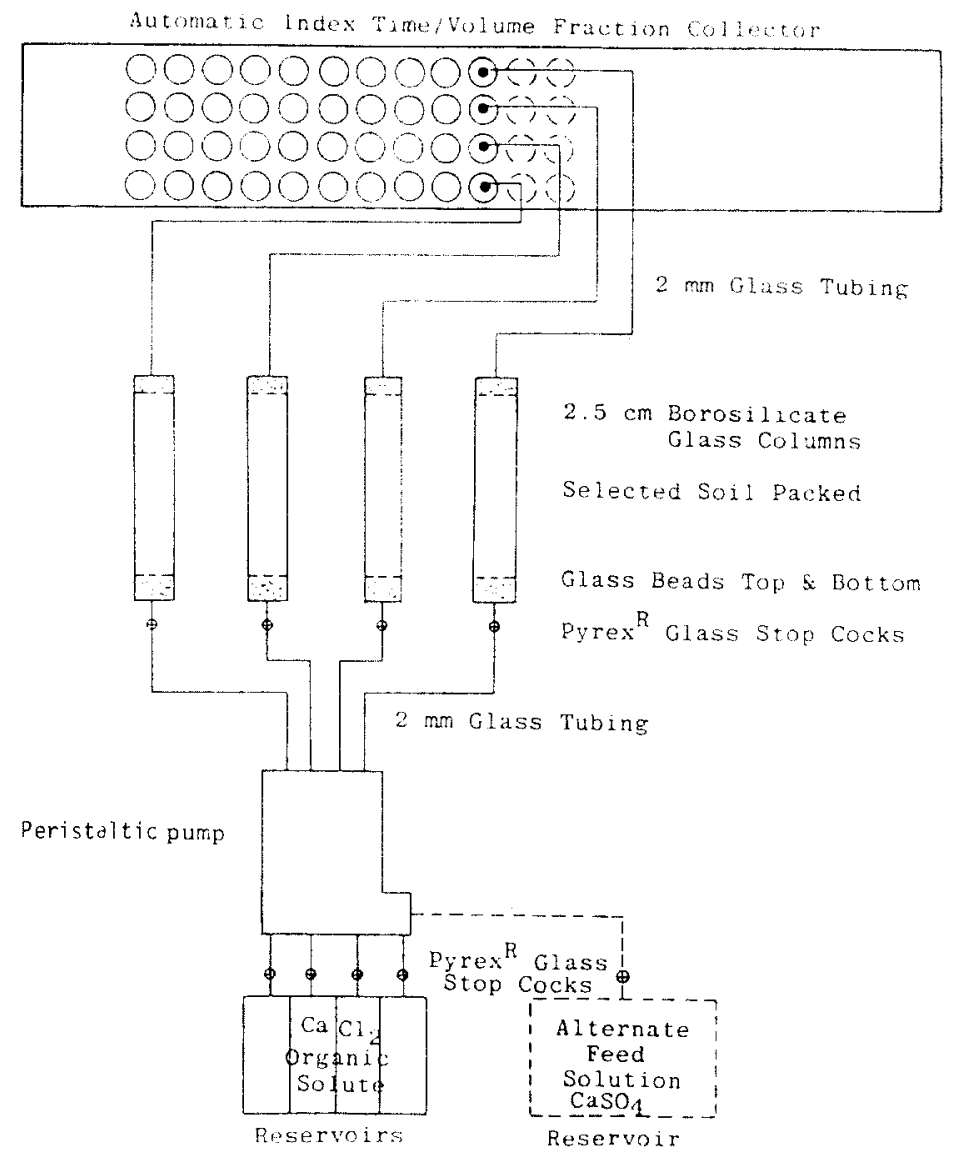

Fig. 1. Schematic illustration of the PFDR soil columns.

eqns. (1)-(3):

$q_{\mathrm{e}}=K_{\mathrm{P}} C_{\mathrm{e}}$

$q_{\mathrm{e}}=K_{\mathrm{F}} C_{\mathrm{e}}^{n}$

$q_{\mathrm{e}}=\frac{Q^{0} b C_{\mathrm{e}}}{1+b C_{\mathrm{e}}}$

where $q_{\mathrm{e}}$ and $C_{\mathrm{e}}$ are the equilibrium solid phase and liquid phase concentrations, respectively, and $K_{\mathrm{P}}, K_{\mathrm{F}}, n, Q^{0}$ and $b$ are characteristic parameters for the several isotherm models. $K_{\mathrm{P}}$ is the familiar linear partitioning coefficient, while $K_{\mathrm{F}}$ and $Q^{0}$ are the sorption capacity related parameters and $n$ and $b$ the sorption intensity related parameters of the Freundlich and Langmuir models, respectively. Linear regression was used to fit data with the linear and Freundlich models while both linear and nonlinear leastsquares analyses were employed for the Langmuir model. Isotherm model 


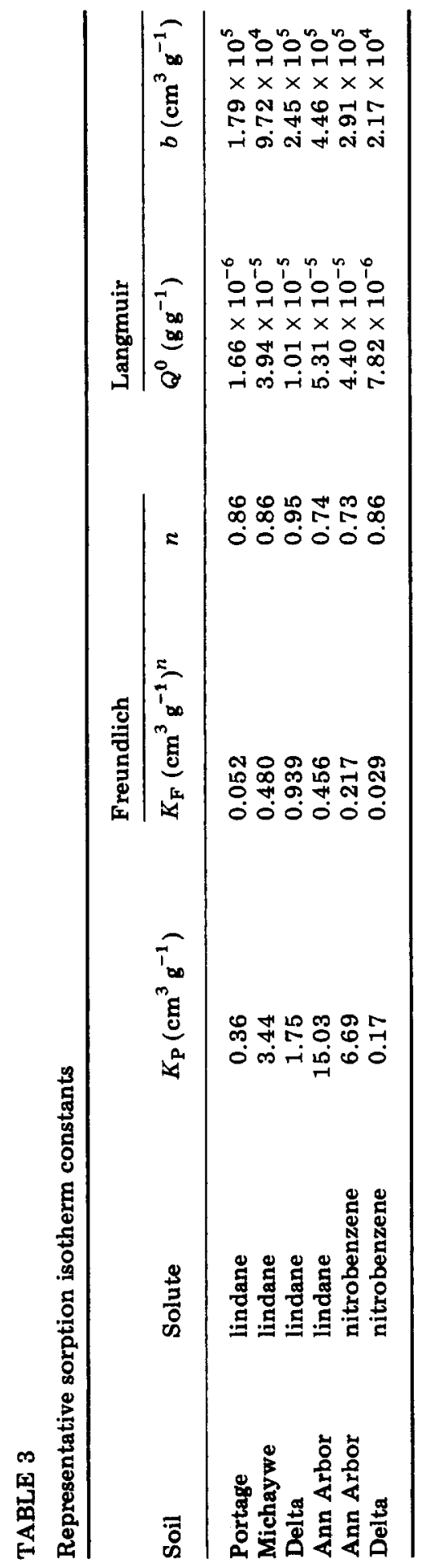




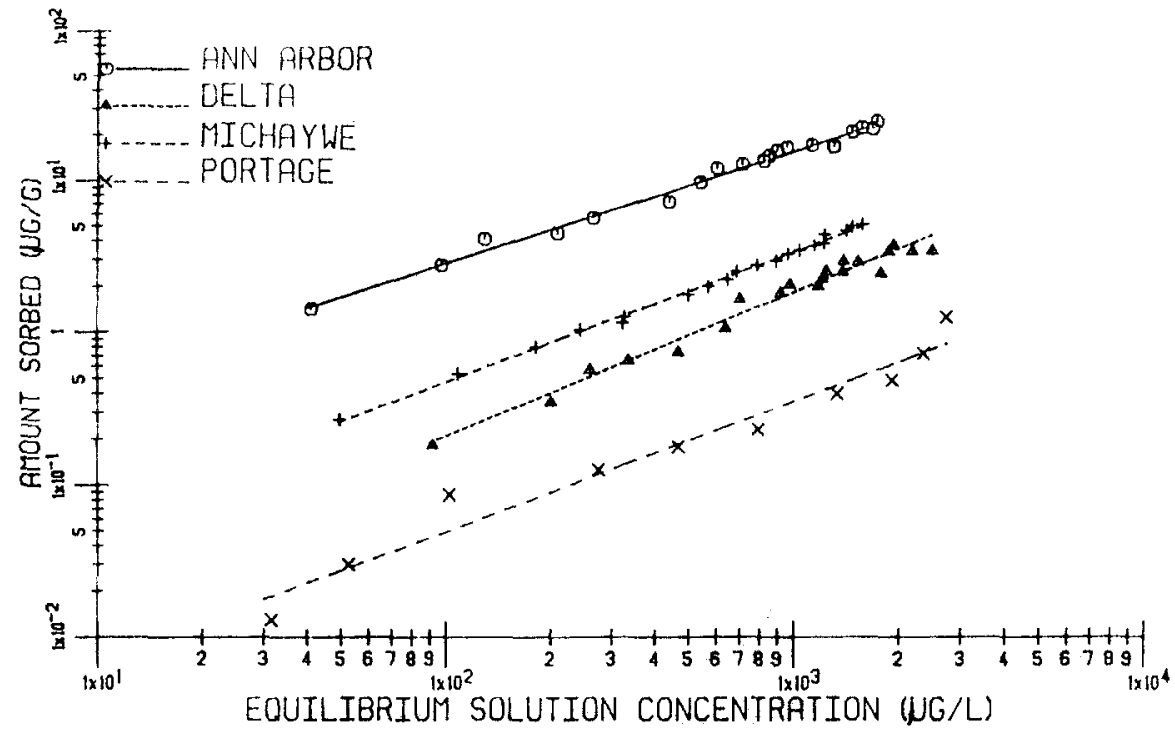

Fig. 2. Experimental data and Freundlich isotherm model fits for lindane.

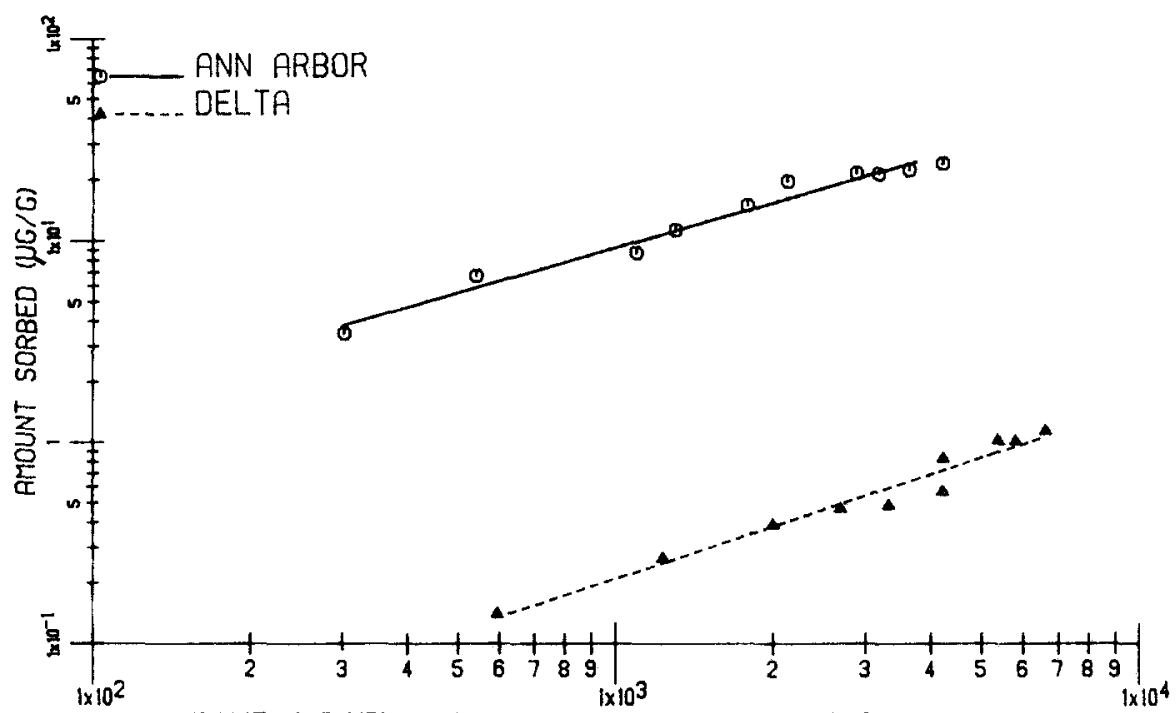

EQUILIBRIUM SOLUTION CONCENTRATION $(\mu \mathrm{G} / L)$

Fig. 3. Experimental data and Freundlich isotherm model fits for nitrobenzene.

parameters are summarized in Table 3 , and Figs. 2 and 3 present experimental data and model fits by the Freundlich equation in a log-log format. The data traces generally exhibited a slightly concave characteristic (rectangular coordinates), and the nonlinear Langmuir and Freundlich isotherm models therefore provided higher levels of correlation than did the linear model.

Karickhoff et al. (1979) investigated a variety of sediments and organic 
TABLE 4

Estimated and observed linear partition coefficients

\begin{tabular}{|c|c|c|c|c|}
\hline Soil & Solute & $\begin{array}{l}\text { Estimated } \\
K_{\mathrm{P}}\left(\mathrm{cm}^{3} \mathrm{~g}^{-1}\right)\end{array}$ & $\begin{array}{l}\text { Observed } \\
K_{\mathrm{P}}\left(\mathrm{cm}^{3} \mathrm{~g}^{-1}\right)\end{array}$ & $\begin{array}{l}\text { Ratio of } \\
\text { estimated } \\
\text { to observed } \\
\text { values }\end{array}$ \\
\hline Portage & lindane & 3.24 & 0.36 & 9.00 \\
\hline Michaywe & lindane & 4.21 & 3.44 & 1.22 \\
\hline Delta & lindane & 3.88 & 1.75 & 2.22 \\
\hline Ann Arbor & lindane & 36.98 & 15.03 & 2.45 \\
\hline Ann Arbor & nitrobenzene & 0.53 & 6.69 & 0.08 \\
\hline Delta & nitrobenzene & 0.056 & 0.170 & 0.33 \\
\hline
\end{tabular}

solutes and concluded that an estimate of the linear sorption partition coefficient could be made on the basis of the organic content of a soil and the octanol: water partition coefficient of a solute according to the empirical approximation:

$\log K_{\mathrm{oc}}=\log K_{\mathrm{ow}}-0.21$

where $K_{\mathrm{oc}}$ is the soil partition coefficient normalized for fraction of organic content and $K_{\mathrm{ow}}$ is the solute octanol : water partition coefficient. Equation (4) was used to develop estimates of linear partition coefficients from the soil and solute properties presented in Tables 1 and 2 for the soil-solute combinations studied. It may be observed by comparison of the estimated and observed values summarized in Table 4 that the former were within a

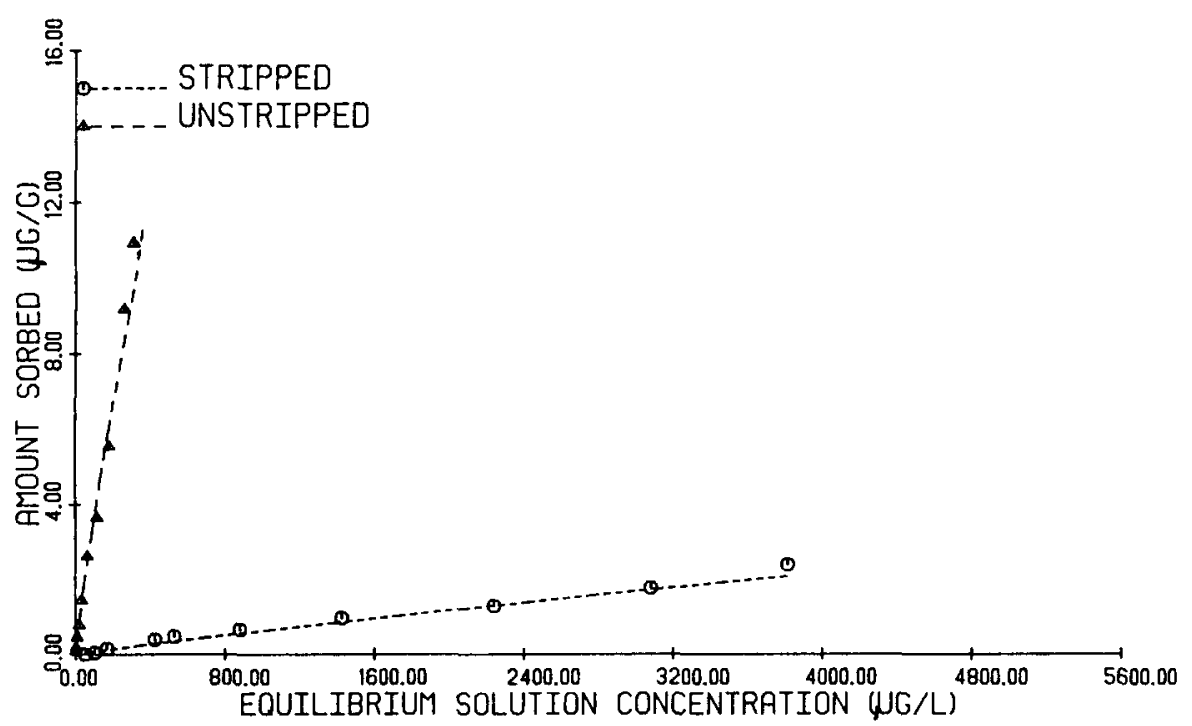

Fig. 4. Comparison of lindane sorption on stripped and unstripped Ann Arbor soil. 
factor of three or four of the observed values for four of the experimental systems. Observed values for the remaining two combinations, Portage soil with lindane and Ann Arbor soil with nitrobenzene, differed by about an order of magnitude from the estimated values. The differences in these two cases are likely due to the low organic carbon content of the Portage soil and to the lower hydrophobicity of the nitrobenzene, factors which would render the empirical correlation given in eqn. (4) less accurate as a predictor of $K_{\text {oc }}$ for these two systems.

To further investigate the importance of soil organic carbon content, an isotherm was performed for the Ann Arbor soil after stripping the organic matter by perchlorate oxidation. Figure 4 presents a comparison of data and associated Freundlich isotherm traces for the stripped and unstripped soils. These results clearly reinforce the importance of organic carbon on the sorption capacity of soils for hydrophobic compounds.

\section{CMBR RATE STUDIES}

Rate studies were performed for a matrix of six soil-solute combinations to investigate the nature of the approach to sorptive equilibrium in CMBR systems. The experimental conditions for these studies are summarized in Table 5, and the results presented in Figs. 5 and 6 along with the dual resistance model fit. Further discussion of this model follows. The results show that the sorption process is rate controlled, requiring several days to approach equilibrium. The trend of an initial rapid rate of sorption followed by a slower sustained rate was observed for each soil-solute combination investigated.

TABLE 5

Bottle point CMBR experimental conditions

\begin{tabular}{lllll}
\hline Soil & Solute & $\begin{array}{l}\text { Mass of } \\
\text { soil }(\mathrm{g})\end{array}$ & $\begin{array}{l}\text { Volume of } \\
\text { solution }\left(\mathrm{cm}^{3}\right)\end{array}$ & $\begin{array}{l}\text { Initial solute } \\
\text { concentration } \\
\left(\mathrm{g} \mathrm{cm}^{-3}\right)\end{array}$ \\
\hline Michaywe & lindane & 12.5 & 25.0 & $5.42 \times 10^{-7}$ \\
Portage & lindane & 30.0 & 15.0 & $5.49 \times 10^{-7}$ \\
Ann Arbor & lindane & 12.5 & 25.0 & $5.90 \times 10^{-7}$ \\
$\begin{array}{l}\text { Delta } \\
\text { Ann Arbor }\end{array}$ & lindane & 12.5 & 25.0 & $3.68 \times 10^{-7}$ \\
Delta & nitrobenzene & 15.0 & 30.0 & $1.89 \times 10^{-6}$ \\
& nitrobenzene & 30.0 & 15.0 & $1.81 \times 10^{-6}$ \\
\hline
\end{tabular}

\section{RATE MODELS}

Several different models have been utilized to mathematically describe sorption rate processes in soil/water systems (Van Genuchten et al., 1974; 


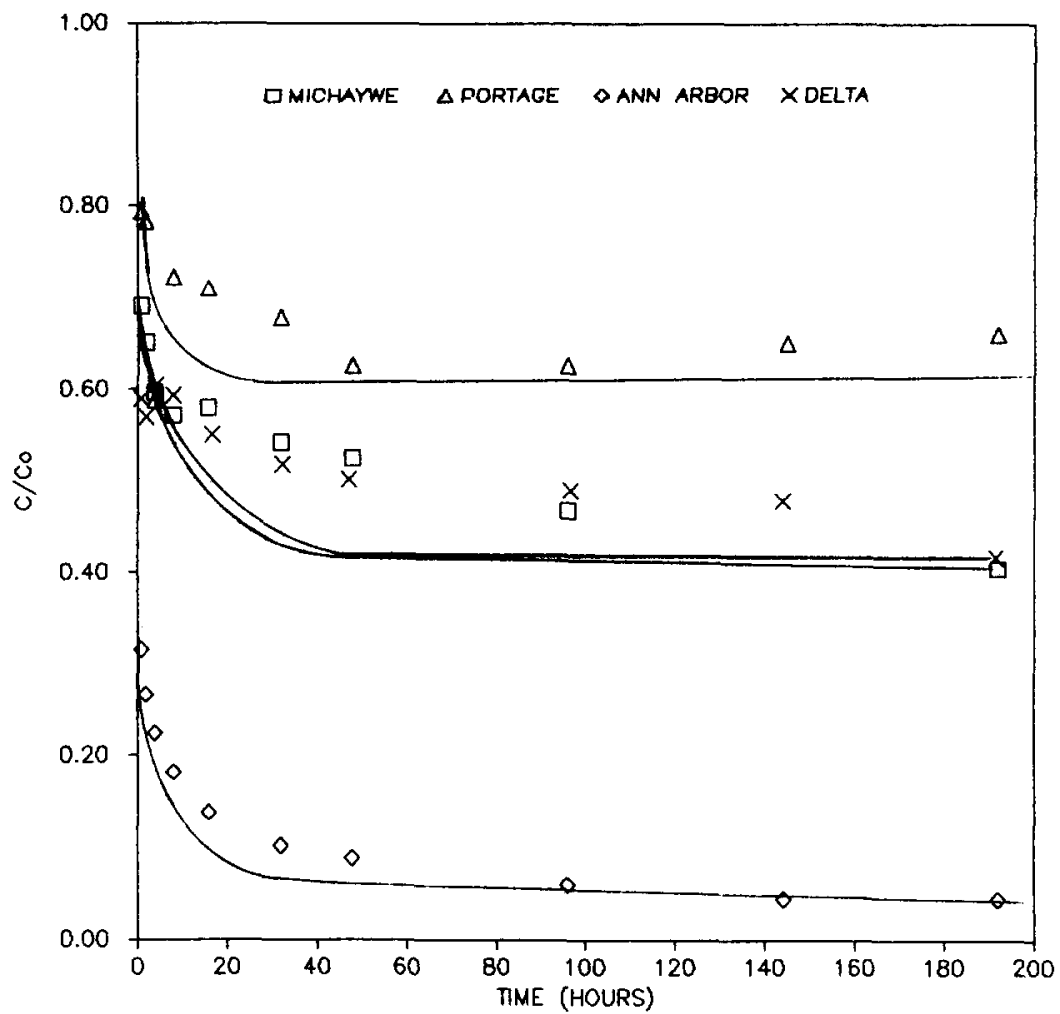

Fig. 5. CMBR sorption rate comparison for lindane with dual resistance model fits.

Van Genuchten and Wierenga, 1976; Cameron and Klute, 1977; Karickhoff, 1980; Hutzler et al., 1984; Miller, 1984; Miller and Weber, 1984). One of the simplest is the first-order rate model, which has the form:

$\frac{\mathrm{d} q}{\mathrm{~d} t}=\alpha\left(q_{\mathrm{e}}-q\right)$

where $q$ is the soil phase solute concentration at any time, $t$, and is a firstorder rate coefficient.

Cameron and Klute (1977) and Karickhoff (1980) noted that the firstorder model is not well suited for describing sorption processes characterized by an initially fast rate of sorption followed by a slower sustained rate and proposed a two-stage model which combines an instantaneous equilibrium reaction with a parallel first-order reaction. The parallel equilibrium/firstorder model may be written in equation form as:

$\frac{\mathrm{d} q}{\mathrm{~d} t}=\alpha\left(q_{\mathrm{e}, \mathrm{k}}-q_{\mathrm{k}}\right)+\frac{\mathrm{d} q_{\mathrm{e}, \mathrm{i}}}{\mathrm{d} C} \frac{\mathrm{d} C}{\mathrm{~d} t}$

where: $C$ is the solution phase concentration of solute at any time $t ; q_{\mathrm{e}, \mathrm{k}}$ and $q_{\mathrm{k}}$ are the soil phase concentrations of solute at equilibrium and as a function 


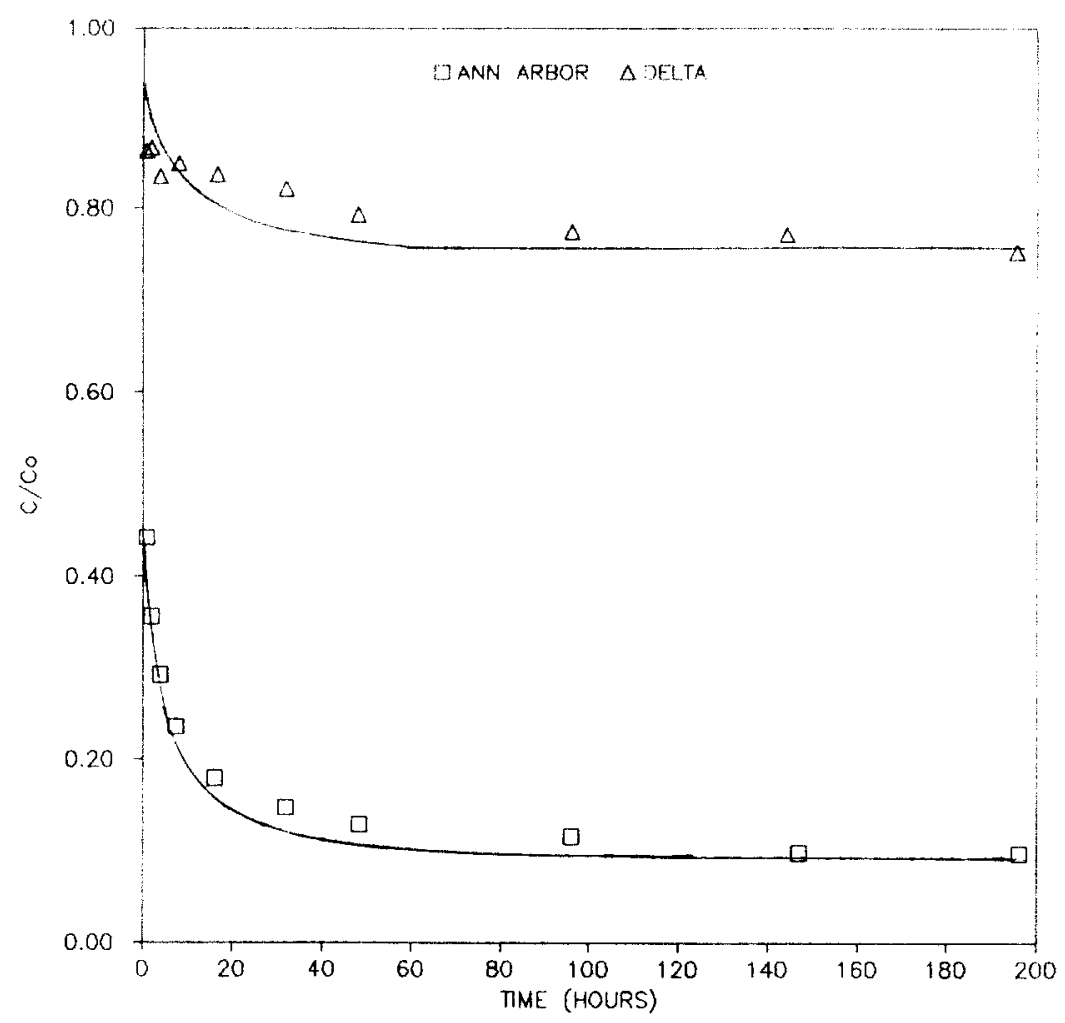

Fig. 6. CMBR sorption rate comparison for nitrobenzene with dual resistance model fits.

of time, respectively, for the rate-controlled portion of the sorption reaction; and $q_{\mathrm{e}, \mathrm{i}}$ is the soil phase concentration for the instantaneously sorbed fraction.

The dual resistance diffusional mass transport model is a conceptually more satisfying model for description of the rate of sorption (Miller, 1984; Miller and Weber, 1984). The dual resistance model describes sorption as a series of mass transfer steps involving molecular diffusion through a boundary layer surrounding a soil particle followed by diffusion within the particle itself. The mathematical representation of the dual resistance diffusion model in spherical coordinates is:

$\frac{\partial q_{\mathrm{r}}}{\partial t}=\frac{D_{\mathrm{s}}}{r^{2}} \frac{\partial}{\partial r}\left(r^{2} \frac{q_{\mathrm{r}}}{\partial r}\right)$

and:

$\frac{\partial q_{\mathrm{r}}}{\partial r}=\frac{k_{\mathrm{f}}}{D_{\mathrm{s}} \rho}\left(C-C_{\mathrm{s}}\right) \quad$ at $\quad r=R$

where: $q_{\mathrm{r}}$ is the soil phase concentration of solute as a function of the radial 
dimension $r ; R$ is the soil particle radius; $C_{\mathrm{s}}$ is the liquid phase equivalent to the soil phase concentration at the exterior of the soil particle; $\rho$ is the soil density; and $k_{\mathrm{f}}$ and $D_{\mathrm{s}}$ are the film and intraparticle mass transfer and diffusion coefficients, respectively.

The several rate models given in eqns. (5)-(8) are presented in general form, and may be incorporated into either a CMBR or PFDR model, or more generally into the three-dimensional tensorial form of the advective-dispersive equation, as long as proper spatial qualification is given to the solid phase concentration terms.

The Ann Arbor/lindane and Ann Arbor/nitrobenzene CMBR rate study data was fitted for the first-order, equilibrium/first-order and dual resistance rate models based on the fundamental CMBR equation:

$\frac{\mathrm{d} C}{\mathrm{~d} t}=\frac{-W}{V} \frac{\mathrm{d} q}{\mathrm{~d} t}$

where $W$ is the weight of soil and $V$ the volume of solution in the reactor. Data fits were derived by adjusting the rate parameters for the appropriate model until a minimum deviation between squared values of the modelgenerated and observed concentrations was attained.

The rate parameter(s) and calculated square errors for the fitted models are presented in Table 6 . These results indicate that better model fits were obtained with the equilibrium/first-order and dual resistance models with the worst results given by the first-order rate model. The dual resistance model approached the behavior of a spherical diffusion model with the external mass transfer coefficient, $k_{\mathrm{f}}$, being insensitive due to the mixing in the CMBR (see also Figs. 7 and 8). Similar results have been reported by Hutzler et al. (1984).

\section{SOIL COLUMN MODELING}

The movement of solute in a soil column can be modeled by a onedimensional form of the advection-dispersion equation:

$\frac{\partial C}{\partial t}=-v \frac{\partial C}{\partial z}+D \frac{\partial^{2} C}{\partial z^{2}} \frac{(1-\epsilon)}{\epsilon} \frac{\partial q}{\partial t}$

where $z$ is the spatial dimension, $v$ is the interstitial velocity, $D$ is the hydrodynamic dispersion and $\epsilon$ is the porosity. The sorption rate models described in eqns. (5)-(8) may be incorporated by substitution for $\mathrm{d} q / \mathrm{d} t$ in the last term on the right-hand side of eqn. (10).

Soil column sorption experiments were performed using Ann Arbor soil and both lindane and nitrobenzene. The experimental conditions for these investigations are summarized in Table 7. Hydrodynamic dispersion parameters were determined from the chloride tracer tests outlined in the 
256

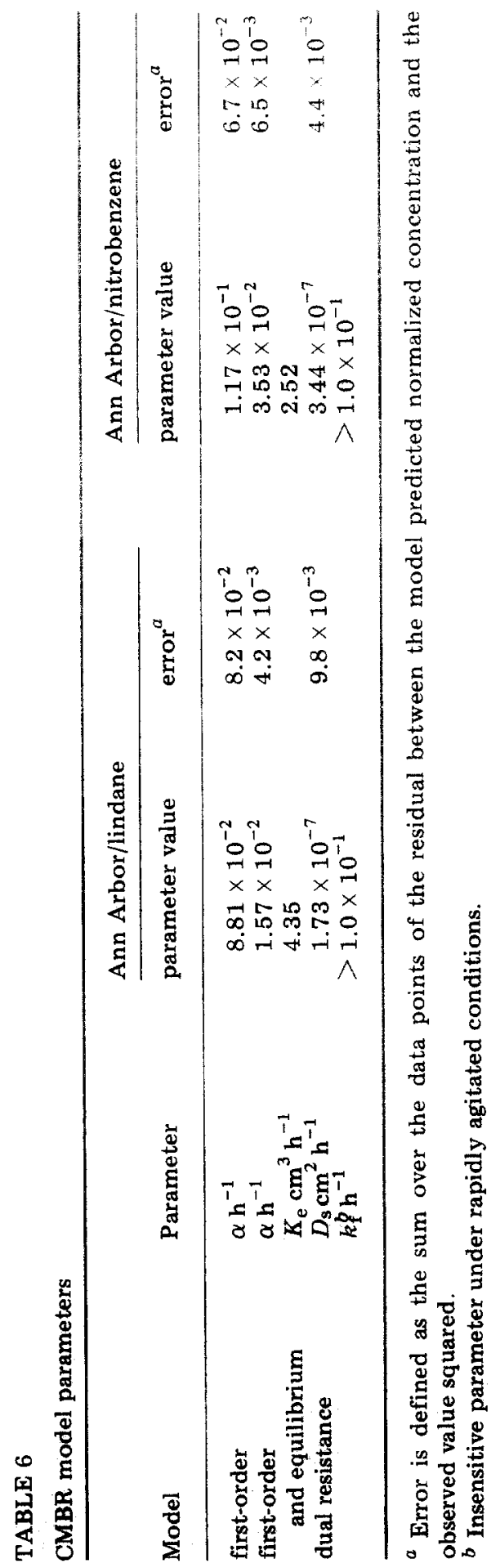




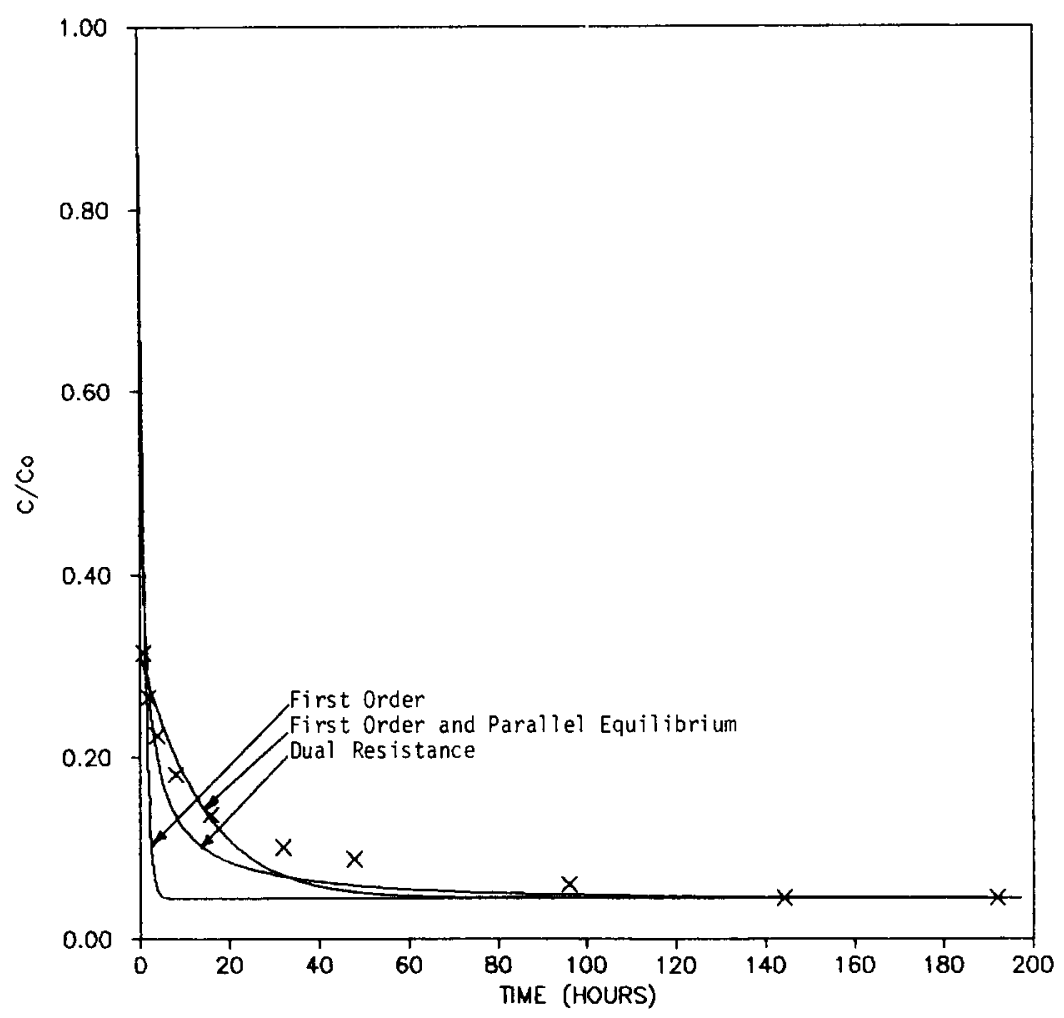

Fig. 7. CMBR sorption rate model comparison for the Ann Arbor soil and lindane.

experimental procedures section. The purpose of the soil column experiments was to investigate the relative predictive abilities of the three different sorption rate modeling approaches using rate parameters derived from the CMBR experiments. Predictions were also made using the linear localequilibrium model to provide a basis for comparison of the rate models to this more traditional approach to the transport modeling. This model assumes that the sorption process is extremely fast relative to the time scale of concern and that the equilibrium sorption isotherm is linear. In equation form the linear local-equilibrium model is:

$\frac{\partial q}{\partial t}=K_{\mathrm{P}} \frac{\partial C}{\partial t}$

Table 8 summarizes the model parameters while Figs. 9 and 10 graphically illustrate the model results. The results indicate that all of the sorption rate models provide better prediction of solute movement than does the linear local-equilibrium model. Among the rate models the same general trend was observed for the PFDR experiments as for the CMBR experiments; namely, the dual resistance model provides the best level of prediction followed closely by the parallel equilibrium/first-order model 


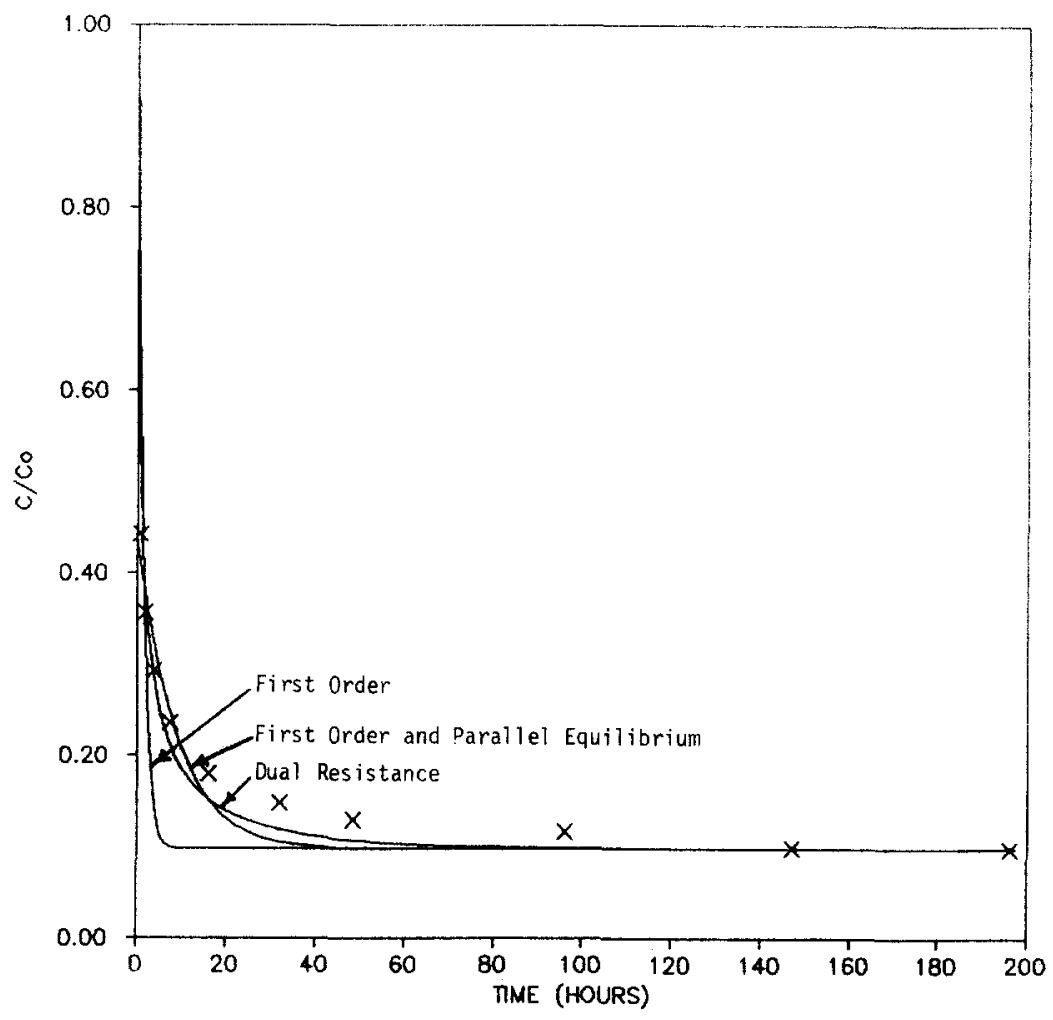

Fig. 8. CMBR sorption rate model comparison for the Ann Arbor soil and nitrobenzene.

and the first-order model respectively. All equilibrium and rate parameters used to predict the soil column sorption were obtained from the CMBR experiments with the exception of the instantaneous fraction of sorption for the parallel equilibrium/first-order model and the film transfer resistance for the dual resistance model, both of which can be expected to vary with changes in hydrodynamic conditions between the CMBR and PFDR and were adjusted accordingly. It may be noted that the best fit value of $K_{e}$ for the nitrobenzene solute-Ann Arbor soil PFDR experiment was equal to

\section{TABLE 7}

PFDR experimental conditions

Ann Arbor/lindane

Ann Arbor/nitrobenzene

\begin{tabular}{lcc}
\hline column length $(\mathrm{cm})$ & 3.0 & 24.5 \\
porosity & 0.38 & 0.40 \\
pore velocity $\left(\mathrm{cm} \mathrm{h}^{-1}\right)$ & 2.21 & 6.56 \\
dispersivity $\left(\mathrm{cm}^{2} \mathrm{~h}^{-1}\right)$ & 0.66 & 3.21 \\
initial concentration $\left(\mu \mathrm{gl}^{-1}\right)$ & 594 & 1433 \\
\hline
\end{tabular}


TABLE 8

PFDR model parameters

\begin{tabular}{|c|c|c|c|}
\hline Model & Parameter & $\begin{array}{l}\text { Ann Arbor/lindane } \\
\text { parameter value }\end{array}$ & $\begin{array}{l}\text { Ann Arbor/nitrobenzene } \\
\text { parameter value }\end{array}$ \\
\hline $\begin{array}{l}\text { linear local } \\
\text { equilibrium } \\
\text { first-order } \\
\text { first-order } \\
\text { and equilibrium } \\
\text { dual resistance }\end{array}$ & $\begin{array}{l}K_{\mathrm{e}} \\
D_{\mathrm{s}} \\
k_{\mathrm{f}}\end{array}$ & $\begin{array}{l}42.4 \mathrm{~cm}^{3} \mathrm{~g}^{-1} \\
8.82 \times 10^{-2} \mathrm{~h}^{-1} \\
1.57 \times 10^{-2} \mathrm{~h}^{-1} \\
3.63 \mathrm{~cm}^{3} \mathrm{~g}^{-1} \\
1.73 \times 10^{-7} \mathrm{~cm}^{2} \mathrm{~h}^{-1} \\
1.80 \times 10^{-2} \mathrm{~h}^{-1}\end{array}$ & $\begin{array}{l}18.6 \mathrm{~cm}^{3} \mathrm{~g}^{-1} \\
1.17 \times 10^{-1} \mathrm{~h}^{-1} \\
3.53 \times 10^{-2} \mathrm{~h}^{-1} \\
0.00 \mathrm{~cm}^{3} \mathrm{~g}^{-1} \\
3.44 \times 10^{-7} \mathrm{~cm}^{2} \mathrm{~h}^{-1} \\
7.20 \times 10^{-3} \mathrm{~h}^{-1}\end{array}$ \\
\hline
\end{tabular}

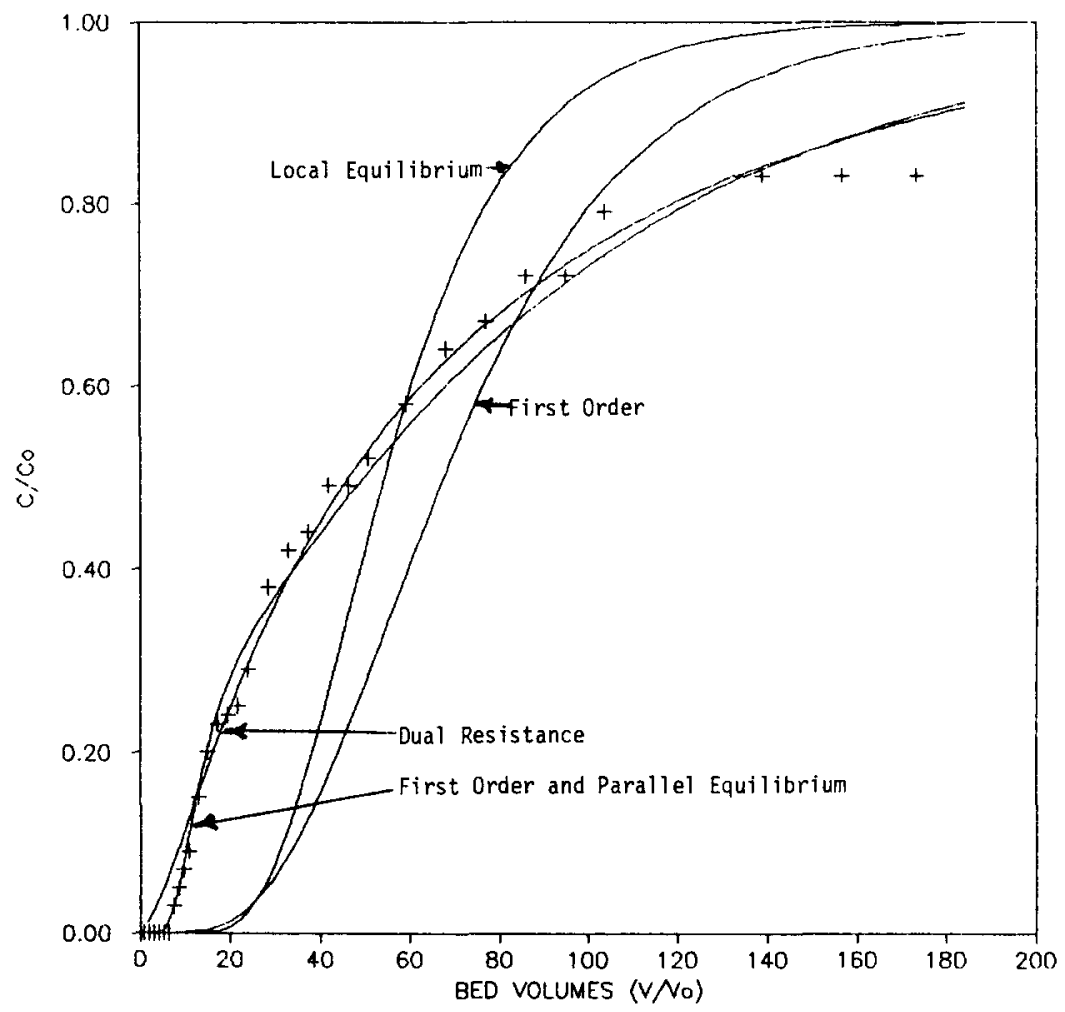

Fig. 9. PFDR sorption rate model comparison for the Ann Arbor soil and lindane.

zero. This may suggest a conceptual problem with the parallel equilibrium/ first-order model, or at least that, the instantaneous fraction sorbed decreases substantially for PFDR systems. 


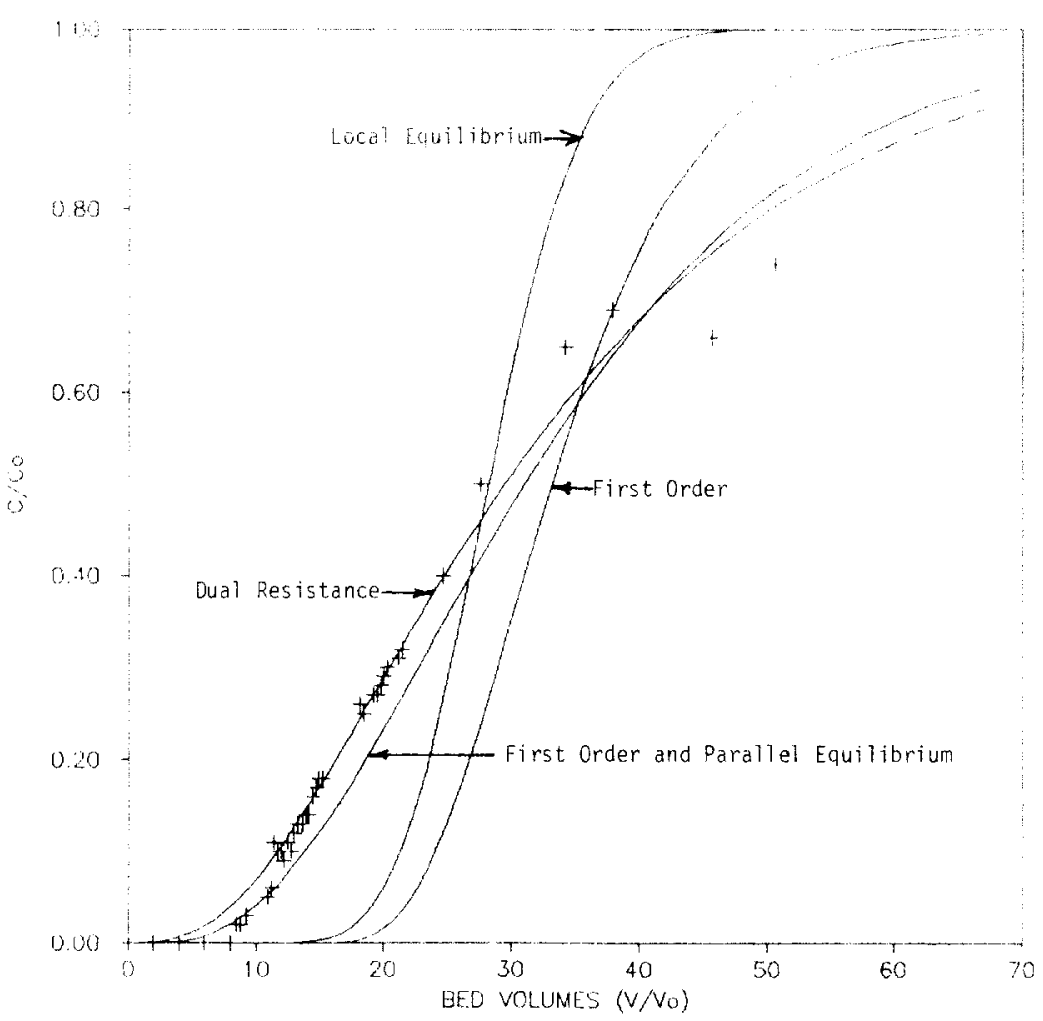

Fig. 10. PFDR sorption rate model comparison for the Ann Arbor soil and nitrobenzene.

\section{CONCLUSIONS}

(1) Sorption equilibrium isotherms for a variety of soils and organic solute systems were found to exhibit nonlinear behavior, especially over large variations in solution phase concentration.

(2) Rates of equilibration were not instantaneous in the systems studied, but rather, after an initially fast rate, several days were required to attain equilibrium.

(3) Several conceptual and mathematical models predicated on nonlinear equilibrium relationships and incorporating rate effects were found to simulate sorption reactions more adequately than models predicated on the assumptions of local equilibrium and linear partitioning.

(4) The parallel equilibrium/first-order model and the dual resistance model were found to be the most suitable models for CMBR data simulations as well as for description of PFDR soil column behavior. 


\section{REFERENCES}

ASTM Standards, Natural Building Stones, Soil and Rock, 1980. Annual Book of ASTM Standards, Part 19. Am. Soc. Test. Mater., Philadelphia, Pa.

Black, C.A., 1965. Methods of soil analysis - Part I. Am. Soc. Agron., Ser. No. 9.

Cameron, D.R. and Klute, A., 1977. Convective-dispersive solute transport with a combined equilibrium and kinetic adsorption model. Water Resour. Res., 13(1): $183-188$.

Hansch, C. and Leo, A.J., 1979. Substituent Constants for Correlation Analysis in Chemistry and Biology. Wiley, New York, N.Y.

Hutzler, N.J., Crittenden, J.C., Oravitz, J.L., Meyer, C.J. and Johnson, A.S., 1984. Modeling groundwater transport of organic compounds. Proc. Environ. Eng. Speciality Confer., A.S.C.E., Los Angeles, Calif., pp. 72-77.

Karickhoff, S.W., 1980. Sorption kinetics of hydrophobic pollutants in natural sediments. In: R.A. Baker (Editor), Contaminants and Sediments, Vol. 2. Ann Arbor Science Publishers, Ann Arbor, Mich., pp. 193-205.

Karickhoff, S.W., Brown, D.S. and Scott, T.A., 1979. Sorption of hydrophobic pollutants in natural sediments. Water Res., 13: 231-248.

Lyman, W.J., Reehl, W.F. and Rosenblatt, D.H., 1982. Handbook of Chemical Property Estimation Methods: Environmental Behavior of Organic Compounds. McGraw-Hill, New York, N.Y.

Miller, C.T., 1984. Modeling of sorption-desorption phenomena for hydrophobic organic contaminants in saturated soil environments. Ph.D. Diss., The University of Michigan, Ann Arbor, Mich.

Miller, C.T. and Weber Jr., W.J., 1984. Modeling organic contaminant partitioning in ground water systems. Ground Water, 22(5): 584-592.

Oceanography International Corporation, 1975. Determination of total organic carbon in sediments and soils. In: Operating Procedures Manual for 05245 Total Carbon System. pp. 10-2-10-4.

Van Genuchten, M.Th. and Wierenga, P.J., 1976. Mass transfer studies in sorbing porous media I. Analytical solutions. Soil Sci. Soc. Am., J., 40: 473-480.

Van Genuchten, M.Th., Davidson, J.M. and Wierenga, P.J., 1974. An evaluation of kinetic and equilibrium equations for the prediction of pesticide movement through porous media. Soil Sci. Soc. Am., J., 41: 278-285. 